\title{
CONDIÇÕES JURÍDICAS INTERNACIONAIS DE INTERVENÇÃO NA AMAZÔNIA
}

\author{
André de Paiva Toledo ${ }^{1}$ \\ Escola Superior Dom Helder Câmara (ESDHC) \\ Kiwonghi Bizawu² \\ Escola Superior Dom Helder Câmara (ESDHC)
}

\section{RESUMO}

Trata-se de um artigo que analisa as condições jurídicas para uma intervenção internacional na Amazônia, enquanto resposta aos danos causados pelo exercício da soberania territorial do Estado, considerando que esse argumento pode ser visto como causa de graves violações ao Direito Internacional. Diante da atual crise amazônica, manifestações de representantes de Estados e textos de especialistas passam a sugerir a necessidade de intervenção na Amazônia. Esta só poderia acontecer como: (i) legítima defesa; ou (ii) operação de manutenção da paz. Na primeira hipótese, é necessário um ataque a ser repelido, o que não existe na atual conjuntura amazônica. Na segunda hipótese, deve haver uma ameaça real à paz internacional, que pode ser identificada com graves violações de direitos humanos, como o são os crimes contra a humanidade, o genocídio e o ecocídio. $\mathrm{Na}$ atual crise amazônica, seria possível cogitar a prática de genocídio e ecocídio, uma vez demonstrada a intenção de inviabilizar a sobrevivência de grupos humanos, como os povos indígenas. Satisfeita essa condição, seria imperativa uma decisão expressa do Conselho de Segurança das Nações Unidas nesse sentido, de modo a garantir a licitude da ação.

Palavras-chave: Amazônia; Conselho de Segurança; ecocídio; genocídio; intervenção; legítima defesa.

1 Doutor em Direito pela Université Panthéon - Assas Paris 2. Mestre e bacharel em Direito pela Universidade Federal de Minas Gerais (UFMG). Professor do Programa de Pós-Graduação em Direito da ESDHC. E-mail: depaivatoledo@gmail.com.

2 Pós-Doutor pela Universidade de Coimbra (UC). Doutor e mestre em Direito pela Pontifícia Universidade Católica de Minas Gerais (PUC - MINAS). Especialista em Direito do Trabalho e Previdenciário pela Universidade Estácio de Sá (UES). Graduado em Direito pela Faculdade de Ciências Jurídicas e Sociais Vianna Júnior (FCJSVJ). ORCID: https://orcid.org/0000-0003-28143639 / e-mail: sebak_07@hotmail.com. 


\section{INTERNATIONAL LEGAL CONDITIONS FOR INTERVENTION IN AMAZON}

\section{ABSTRACT}

This article analyzes the legal conditions for an international intervention in Amazon, as a response to damages caused by the exercise of territorial sovereignty of the State, which can be seen as a result for serious violations of international law. In the face of the current Amazonian crisis, statements by State representatives and expert texts have suggested the necessity for intervention in Amazon. It could only happen as (i) a legitimate defense or (ii) peacekeeping operation. In the first hypothesis, it is necessary an attack to be repelled, which does not exist in the current Amazonian conjuncture. In the second case, there must be a real threat to international peace, which can be identified with serious violations of human rights, such as crimes against humanity, genocide and ecocide. In the current Amazonian crisis, it would be possible to consider the practice of genocide and ecocide, once demonstrated the intention to make impossible the survival of human groups such as indigenous peoples. If this condition is considered, an express decision by the United Nations Security Council would be imperative to ensure the lawfulness of the action.

Keywords: Amazon; ecocide; genocide; intervention; Security Council; self-defense. 


\section{INTRODUÇÃO}

A Amazônia não é patrimônio comum da humanidade, pois não há em vigor qualquer sistema jurídico que institua um mecanismo de gestão internacionalizada do espaço onde se encontra o bioma amazônico, como acontece, por exemplo, na Área ${ }^{3}$. A Amazônia não é patrimônio mundial, salvo o Complexo de Conservação da Amazônia Central (Amazonas, Brasil), que desde 2000, está inscrito na Lista do Patrimônio Mundial Natural da Organização das Nações Unidas para a Educação, a Ciência e a Cultura (UNESCO).

A Amazônia é, por sua vez, patrimônio internacional, pois se encontra naturalmente espalhada pelo território nacional de nove diferentes Estados. Logo, os destinos da Amazônia não interessam a apenas um país, por mais extenso que seja seu território ${ }^{4}$. Pelo mesmo motivo, pode-se afirmar que a Amazônia é patrimônio nacional de cada um desses Estados, que ali exercem sua soberania territorial, consequentemente, tendo o direito de explorar e aproveitar seus recursos naturais para o desenvolvimento socioeconômico desses.

A Amazônia é também preocupação comum da humanidade, pois sua proteção implica na preservação de sua rica biodiversidade, na manutenção de um importante fixador de carbono para o enfrentamento global dos desafios inerentes às mudanças climáticas, no equilíbrio do balanço hidrológico, que influencia o regime global de chuvas, e na garantia do respeito aos direitos humanos das populações locais. Em um contexto internacional pós-nazismo, a paz, a segurança, a dignidade humana e o desenvolvimento sustentável tornam-se a base de sustentação das Relações Internacionais. A Amazônia insere-se, portanto, como tópico especial em todas essas dimensões, o que faz urgente o exame das consequências jurídicas internacionais do modelo de gestão do território, adotado pelos Estados amazônicos, especialmente o Brasil.

O Direito Internacional é construído sobre o princípio da soberania, segundo o qual os diversos Estados são livres para determinar as estratégias de utilização de seu território. Contudo, a soberania territorial é autolimitada em uma perspectiva democrática das relações políticas

3 A Área são os fundos marinhos existentes para além da plataforma continental dos Estados costeiros, que é patrimônio comum da humanidade gerido, nos termos da Parte XI da Convenção das Nações Unidas sobre o Direito do Mar (1982), pela Autoridade Internacional dos Fundos Marinhos.

4 Dos nove países da região Pan-amazônica, o Brasil destaca-se por ter, em seu território, cerca de $60 \%$ do bioma amazônico. 
(COSTA, 2011), por meio da construção de normas jurídicas, que proíbem que seu exercício por um Estado cause danos significativos a outros sujeitos de Direito Internacional. Ao longo do tempo, os limites jurídicos ao exercício da soberania têm se fundado em diversos aspectos, notadamente na valorização da dignidade humana e do meio ambiente equilibrado.

Um ato imputado ao Estado, que viole obrigação jurídica internacional, pode ser objeto de responsabilização, em razão do interesse de agir de quem tem o direito violado, seja Estado, seja organização ou sejam os indivíduos (PIOVESAN, 2003). As reações à violação do Direito Internacional devem ser, em regra, pacíficas.

Desde os anos de 1980, os Estados amazônicos ${ }^{5}$ têm enfrentado, no âmbito das Relações Internacionais, a imputação por violação de direitos humanos e direitos ambientais, quando da utilização de seu território nacional. Mais recentemente, em razão da divulgação de dados acerca da aceleração do desmatamento e queima da Amazônia brasileira e boliviana, tem havido manifestações acerca da violação do Direito Internacional e das possíveis respostas por parte dos sujeitos envolvidos. Destacam-se aqui as manifestações de representantes de Estados e organizações internacionais, com destaque para o presidente da França, Emmanuel Macron, e a publicação de artigos em periódicos, que têm levado à pergunta que esta pesquisa pretende responder: é possível uma intervenção na Amazônia à luz do Direito Internacional?

Por se tratar de desdobramento contemporâneo de uma temática que nunca deixou de interessar à comunidade internacional, envolvendo a preservação ambiental e a proteção da dignidade humana na Amazônia, em contexto de universalização dos direitos humanos e do combate às mudanças climáticas - em o Direito Internacional para a humanidade, Cançado Trindade (2005) -, justifica a análise da possibilidade, à luz do Direito Internacional em vigor, de haver ali uma intervenção.

Para tanto, em um primeiro momento, faz-se necessária a apresentação dos fatos, que permitem a constatação de haver uma crise internacional amazônica, que justificaria extraordinariamente uma intervenção. Em seguida, analisa-se o Direito Internacional em vigor, no que concerne à intervenção, pondo em evidência as condições jurídicas para sua realização. Por fim, faz-se a conjugação dessas hipóteses com os fatos, concluindo que uma intervenção na Amazônia, no contexto atual, só seria

5 São Estados da amazônicos: Bolívia, Brasil, Colômbia, Equador, França, Guiana, Peru, Suriname e Venezuela. 
possível após decisão do Conselho de Segurança das Nações Unidas, em razão da existência de prática de grave violação de direitos humanos, associada ao direito à propriedade coletiva de povos indígenas, diante da não demarcação de terras indígenas pelo Estado, e à destruição ambiental como estratégia de expulsão e extermínio de populações locais.

\section{CRISE INTERNACIONAL AMAZÔNICA}

Em 22 de agosto de 2019, o presidente da França declarou que: "Notre maison brûle. Littéralement. L'Amazonie, le poumon de notre planète qui produit $20 \%$ de notre oxygène, est en feu. C'est une crise internationale. Membres du G7, rendez-vous dans deux jours pour parler de cette urgence" (MACRON, 2019). No mesmo sentido, o primeiro-ministro britânico declarou que: "The fires ravaging the Amazon rainforest are not only heartbreaking, they are an international crisis"7 (JOHNSON, 2019).

Partindo da premissa de que a Amazônia é o pulmão do mundo, o que é contestado (SILVEIRA, 2009), a afirmação dos representantes da França e Reino Unido impressiona e não é desarrazoada: há uma crise internacional, em razão da aceleração do desmatamento e queimada do bioma amazônico.

Apesar de não ser o principal produtor ${ }^{8}$ de oxigênio, a floresta amazônica é um gigantesco reservatório de carbono. No momento em que a floresta é queimada, há a liberação na atmosfera do dióxido de carbono, que contribui para o efeito estufa. Logo, a Amazônia não é o pulmão do planeta por conta da produção de oxigênio, mas é uma gigantesca represa de carbono (TOLEDO, 2012, p. 115). Há, portanto, uma importância inquestionável da Amazônia para a manutenção do equilíbrio ambiental e a minimização dos prejuízos advindos do efeito estufa e das mudanças climáticas (TOLEDO, 2015).

Apesar de os países amazônicos não serem os maiores emissores de gases de efeito estufa, é significativa a contribuição do desmatamento e queima da floresta amazônica para o aumento do volume de emissão desses gases. Além disso, a destruição florestal é também causa de perda

\footnotetext{
6 "Nossa casa queima. Literalmente. A Amazônia, o pulmão de nosso planeta, que produz $20 \%$ de nosso oxigênio, está em chamas. É uma crise internacional. Membros do G7, se reunirão em dois dias para tratar desta urgência".

7 "Os incêndios que devastam a floresta amazônica não são apenas devastadores, são uma crise internacional".

8 A maior parte do oxigênio atmosférico é produzido por fitoplâncton.
} 
da mais rica biodiversidade terrestre. Pode-se, portanto, afirmar que a constante e sistemática diminuição da cobertura vegetal nativa aumenta a vulnerabilidade climática de todos os Estados.

Durante a campanha eleitoral, em 2018, o candidato à presidência do Brasil, Jair Bolsonaro, prometia ao eleitorado desconstruir a política nacional de combate ao desmatamento. Ele sugeriu retirar o Brasil do Acordo de Paris sobre mudanças climáticas ("SE NÃO MUDAR...", 2018); reduzir o tamanho das unidades de conservação (AMORIM, 2019); não demarcar terras indígenas (PUTTI, 2019) e viabilizar o aproveitamento econômicos dos recursos minerais encontrados nessas terras tradicionais (SOUZA, 2019), em especial o ouro (SASSINE, 2019).

Uma vez eleito, Bolsonaro tem tomado ou deixado de tomar medidas, causando uma piora significativa de índices socioambientais na Amazônia. De fato, entre janeiro e julho de 2019, o Instituto Nacional de Pesquisas Espaciais (INPE) registrou 15.924 focos de queimada na Amazônia, o que corresponde a um crescimento de $35,6 \%$ em relação ao mesmo período de 2018. Só em junho de 2019, houve o aumento de $84 \%$ das queimadas e $278 \%$ do desmatamento, em comparação com os dados obtidos em junho de 2018 (INPE, 2019). No mês de agosto, o INPE identificou o aumento de 222\% do desmatamento da Amazônia (WATANABE, 2019).

A criação de um sistema jurídico internacional para o desenvolvimento sustentável, desde a década de 1980, não tem sido suficiente para garantir que os recursos naturais sejam utilizados sem comprometer o equilíbrio ambiental. Não se trata, portanto, de uma particularidade amazônica, mas da generalidade planetária. A insustentabilidade é característica do próprio capitalismo (MARQUES, 2015). Qualquer tentativa de alteração do padrão global de exploração insustentável dos recursos naturais e a consequente deterioração das coordenadas ecológicas passa necessariamente pela reformulação do modelo econômico. Não só na Amazônia, mas em todo o planeta.

De toda forma, o vigente sistema jurídico internacional caracteriza-se por reafirmar o princípio da soberania nacional sobre os recursos naturais. De fato, o princípio 21 da Declaração de Estocolmo sobre Meio Ambiente Humano (1972) determina que os Estados são soberanos para explorar seus recursos naturais, em conformidade com sua própria política ambiental. No mesmo sentido, o princípio 2 da Declaração do Rio de Janeiro sobre Meio Ambiente e Desenvolvimento (1992) reiterou que os Estados têm o direito soberano de explorar seus próprios recursos, segundo suas 
políticas de desenvolvimento sustentável. Também a Convenção sobre Diversidade Biológica (1992), em seu art. 3ㅇ, estabelece que os Estados, em conformidade com a Carta das Nações Unidas e os princípios gerais do Direito Internacional, têm o direito de explorar e aproveitar seus próprios recursos biológicos, segundo suas próprias políticas ambientais. Por fim, a Convenção-quadro sobre Mudanças Climáticas (1992), em seu preâmbulo, lembra que os Estados têm o direito soberano de explorar seus próprios recursos segundo suas políticas ambientais e de desenvolvimento.

Reafirmada a soberania dos Estados sobre seu território e recursos naturais, isso não significa que os Estados possam abusar de seus direitos soberanos. Ao contrário, a exploração dos recursos naturais, encontrados em um determinado território, deve ser feita pelo Estado titular do direito em conformidade com suas obrigações jurídicas.

É obrigação erga omnes não causar danos significativos ao meio ambiente de outros Estados ou de espaços internacionalizados, quando do exercício por um Estado de sua soberania territorial. Dessa forma, os Estados devem tomar todas as medidas para garantir que as atividades realizadas em seu território se deem licitamente. Nesse sentido, caso um Estado permita, por ação ou omissão, a prática de atos que causem danos significativos ao meio ambiente de outro Estado ou ao meio ambiente internacionalizado, há aí a violação do Direito Internacional (UNITED NATIONS, 2006). Em virtude dessa violação, o Estado ao qual é imputado o dano transfronteiriço causado, vincula-se à obrigação de repará-lo. Por sua vez, os sujeitos de Direito Internacional, que sofrem os danos causados, têm interesse de agir em face daquele Estado, demandando a reparação. Trata-se da lógica inerente ao sistema jurídico internacional.

A atual crise internacional amazônica não tem dado margem ao questionamento da soberania territorial dos Estados amazônicos (THE ECONOMIST, 2019), apesar do jornal francês Le Monde ter publicado que o Estado francês considera ser a Amazônia "un bien commun universel"" (L'AMAZONIE..., 2019). O próprio presidente da França afirmou que o status internacional da Amazônia "est un chemin qui reste ouvert, qui continuera de prospérer dans les prochains mois et années, car l'enjeu est tel sur le plan climatique qu'on ne peut pas dire 'Ce n'est que mon problème" $" 10$ (AMAZONIE..., 2019).

\footnotetext{
9 "um bem comum universal".

10 "é um caminho que permanece aberto, que continuará a prosperar nos próximos meses e anos, pois o desafio é tal no nível climático que não se pode dizer 'Esse problema é só meu"”.
} 
Isso não significa que a crise internacional amazônica impeça a discussão sobre desdobramentos jurídicos diferentes da internacionalização. Ao contrário, manifestações recentes têm levantado a hipótese de adoção de medidas jurídicas extraordinárias. Percebendo isso, o ex-comandante do Exército Brasileiro, Eduardo Villas Bôas, declarou que: "Com uma clareza dificilmente vista, estamos assistindo a mais um país europeu, dessa vez a França, por intermédio de seu presidente Macron, realizar ataques diretos à soberania brasileira, que inclui, objetivamente, ameaças de emprego do poder militar" (VILLAS BOAS, 2019).

Diante da atual crise internacional amazônica e as especulações acerca das consequências jurídicas internacionais, torna-se urgente a discussão acerca da possibilidade de intervenção na Amazônia, que é uma das respostas previstas para situações de crise internacional.

\section{NÃO INTERVENÇÃO: PRINCÍPIO JURÍDICO INTERNACIONAL}

Com a adoção em São Francisco (Estados Unidos) da Carta das Nações Unidas, nos termos de seu art. $2^{\circ}, \S 4^{\circ}$, os Estados membros devem evitar a ameaça ou o uso da força nas Relações Internacionais, que possam comprometer a integridade territorial ou independência política de qualquer Estado, inclusive os eventuais não membros. A intenção declarada de usar a força em certos eventos, pode constituir uma ameaça que é proibida (CIJ, 1996).

Como desdobramento dos princípios da soberania, autodeterminação e igualdade, identifica-se o princípio da não intervenção. Pretende-se assim evitar que Estados se aproveitem de uma posição favorável em termos econômicos ou militares para penetrar na esfera de competência exclusiva de outro Estado, com o intuito de ajudar a resolver seus assuntos, resolver em seu lugar, ou obrigar a resolver conforme sua vontade (DIHN; DAILLIER; PELLET, 2003).

Nos termos do art. $2^{\circ}, \S 7^{\circ}$, do mesmo instrumento, assim como acontece com os demais integrantes da comunidade internacional, as Nações Unidas per se não podem intervir nos assuntos internos dos Estados membros, que não são obrigados a apresentá-los em um foro internacional. Em consonância com essa opção convencional, a Corte Internacional de Justiça, ao julgar o Caso das Atividades militares, envolvendo a Nicarágua e os Estados Unidos, confirmou a proibição de que os Estados intervenham 
direta ou indiretamente, individual ou coletivamente, no domínio reservado dos demais Estados. Sendo assim, como a gestão do território faz parte do domínio reservado do Estado, os demais integrantes da comunidade internacional não podem pretender realizar ali uma intervenção estrangeira ou internacional (CIJ, 1984).

\subsection{Exceção ao princípio da não intervenção}

Há exceções ao princípio da não intervenção. Estados podem intervir em outro Estado tão somente nas hipóteses previstas na própria Carta das Nações Unidas. Para além dessa moldura de validade, qualquer iniciativa se torna ato ilícito internacional. Logo, a vedação do uso da força nas Relações Internacionais não é absoluta, mas extraordinária (DIHN; DAILLIER; PELLET, 2003, p. 452). Estabelece-se assim uma conjuntura jurídica, de acordo com a qual a soberania dos Estados, especialmente daqueles mais frágeis em termos econômicos e militares, seja protegida contra iniciativas de tipo colonialista. Dentro dessa lógica, é contrário ao Direito Internacional o direito de conquista como estratégia de apropriação territorial (CHAGAS; HECKTHEUER; HECKTHEUER, 2017, p. 853).

Como mencionado, o princípio da não intervenção está diretamente ligado ao princípio da "igualdade soberana" (COLOMBO, 2008, p. 7). De fato, nos termos do art. $1^{\circ}, \S 2^{\circ}$, da Carta das Nações Unidas, é propósito daquela organização internacional fomentar Relações Internacionais amistosas, baseadas no respeito ao princípio de igualdade de direitos e autodeterminação dos povos, em que a intervenção seja vista como remédio excepcional.

Dessa forma, há situações extraordinárias em que o próprio sistema jurídico internacional reconhece o direito de um Estado ou grupo de Estados de intervir em outro Estado. Para que a intervenção seja lícita, é necessário que esteja em conformidade com o disposto na Carta das Nações Unidas ${ }^{11}$ ou de outro mecanismo do qual participe livremente o Estado onde ocorrerá a intervenção. Mesmo em caso de intervenção conduzida por outras organizações internacionais, é necessário que sejam seguidos os princípios estabelecidos na Carta das Nações Unidas e que essa organização internacional seja comunicada sobre todas as medidas tomadas (HOFFMANN, 2003).

11 Todos os nove Estados da Pan-Amazônia são membros das Nações Unidas e estão, consequentemente, vinculados entre si pela Carta das Nações Unidas. 


\section{USO DA FORÇA NO DIREITO INTERNACIONAL}

A Carta das Nações Unidas prevê que os Estados membros daquela organização internacional podem fazer o uso da força em duas hipóteses estritas: legítima defesa ou cumprimento de decisão do Conselho de Segurança. Nessas hipóteses, o princípio da não intervenção é afastado.

\subsection{Legítima defesa}

No exercício da legítima defesa, cabe ao Conselho de Segurança verificar sua pertinência, determinando se existe realmente ato de agressão ou se o ato é justificável enquanto domínio reservado ao Estado. De fato, o art. 51 da Carta das Nações Unidas determina que nada compromete o direito inerente à legítima defesa, a não ser que ocorra um ataque armado contra um Estado membro. Isso significa que o direito à legítima defesa existe apesar do Conselho de Segurança. Trata-se de direito erga omnes inerente ao próprio Direito Internacional (DIHN; DAILLIER; PELLET, 2003).

Embora a legítima defesa possa ocorrer previamente, é necessário que o Conselho de Segurança faça o controle de convencionalidade do ato do Estado. Quando isso se dá, pode-se constatar que não se tratava de situação para a defesa legítima, o que torna ilícito o uso da força ab initio. Por isso, tal direito deve ser exercido com muita prudência pelos Estados. Se, por sua vez, o Conselho de Segurança verificar ter havido realmente um ato de agressão, o emprego da força proporcional é considerado um exercício regular do direito.

Logo, para que a legítima defesa seja um ato internacionalmente lícito, é necessário que o Estado, que a exerce, tenha sido previamente agredido. Há que ter sido praticado um ato de agressão por outro Estado, o que corresponde à violência "armada" (DIHN; DAILLIER; PELLET, 2003, p. 960). De fato, nos termos da Resolução 3314 (XXIX) da Assembleia Geral das Nações Unidas, ato de agressão é o emprego da força armada por um Estado contra a soberania, integridade territorial ou independência política de outro Estado. Com base no direito humanitário, o ataque é sempre praticado por forças militares (SCHMITT, 2011), a fim de causar dano ao inimigo (VITÉ, 2009).

Sobre o tema, a Corte Internacional de Justiça afirmou que os Estados têm o "direito fundamental" à sobrevivência (CIJ, 1996). Sempre que esta estiver em risco, mesmo em circunstâncias em que não há o emprego de 
armas, seria possível o exercício do direito de legítima defesa pelo Estado ameaçado. Contudo, o ato não armado deve ser extremamente grave, em que se compromete a própria existência do Estado como tal. De qualquer forma, seja armado ou não, a legítima defesa pressupõe um ataque, que é sempre intencional (DINSTEIN, 2004).

Pode-se imaginar que um ataque ambiental possa ser feito ao território de um Estado, dando-lhe a possibilidade de se defender legitimamente. Além de grave, o dano ambiental transfronteiriço deve ser a finalidade da ação praticada. Não basta que a origem do dano seja o espaço de jurisdição ou controle de um Estado, não basta que haja o risco de ocorrência de um dano significativo transfronteiriço, é necessário que a finalidade da ação seja atacar o Estado vizinho, colocando em risco sua existência como Estado.

É possível imaginar, por exemplo, incursões diretas de poluição ou substâncias perigosas no território de Estados vizinhos, com a intenção de lhes causar graves danos, o que pode ser interpretado como um ataque a ser repelido pela legítima defesa. Da mesma forma, as consequências ambientais da utilização de estruturas químicas, biológicas ou nucleares podem também ser interpretadas como atos de ataque, dependendo da intencionalidade a ser demonstrada caso a caso (ECKERSLEY, 2007).

Evidentemente, a preocupação de um Estado com seu meio ambiente natural é um interesse essencial, que lhe dá o direito de se defender pelos meios previstos no Direito Internacional (CIJ, 1997). Porém, não é por ser o meio ambiente um interesse essencial do Estado que este passa a ter o direito de intervir no domínio reservado dos demais Estados. Um dano ambiental só seria suficiente para dar margem à legítima defesa ao demonstrar-se, na realidade, como um dano suficiente para extinguir o Estado $^{12}$.

\subsection{Legítima defesa estrangeira na Amazônia}

Em 5 de agosto de 2019, Stephen M. Walt ${ }^{13}$ publicou art. em Foreign Policy, sustentando que uma intervenção estrangeira na Amazônia é questão de tempo, até que as "grandes potências" ajam para interromper

12 A título de exemplo, podemos citar o desafio que enfrentam alguns países insulares (Maldivas, Nauru, Tuvalu, Fiji, Kiribati, Ilhas Marshall etc.), cujos territórios terrestres estão ameaçados pelo aumento do nível do mar, em razão dos efeitos das mudanças climáticas. Para que esses países pudessem agir em legítima defesa, seria necessário identificar o Estado responsável pelas mudanças climáticas. Com absoluta certeza, pode-se afirmar que tal Estado não é o Brasil. Vide Trindade (2019).

13 Stephen M. Walt é professor de Relações Internacionais da Harvard University (Cambridge, Estados Unidos). 
as mudanças climáticas. Walt identifica a responsabilidade do Estado brasileiro pelo aumento das mudanças climáticas, que colocam em risco a sobrevivência de outros Estados, o que justificaria o exercício da legítima defesa. "Brazil happens to be in possession of a critical global resource for purely historical reasons - and its destruction would harm many states if not the entire planet"14 (WALT, 2019).

A legítima defesa de um Estado estrangeiro só seria possível na Amazônia, caso o processo de desflorestamento fosse tratado como um ataque intencional contra outro Estado, isto é, "qualquer operação ou ato com o efeito de infringir um prejuízo ou dano no Estado e nos seus elementos fundamentais" (GOUVEIA, 2013, p. 181). Quando o Estado brasileiro exerce sua soberania territorial, implicando a aceleração do processo de desmatamento e queima da Amazônia, não há a intenção de pôr em risco a existência de outros Estados. Logo, não há ataque por meio dos danos ambientais causados e, consequentemente, não há possibilidade de legítima defesa por parte de outros Estados.

Descabida é, portanto, a teoria de Walt, que interpreta o que ocorre na Amazônia como um ato de agressão a ser respondido pelo exercício da legítima defesa das grandes potências militares. Não há qualquer demonstração de que o Estado brasileiro tenha a intenção de causar dano significativo a outros Estados, com destaque para a vizinha França, por meio da destruição do bioma amazônico. De fato, a Guiana Francesa compõe o Estado francês, o que permite que o presidente daquele país afirme que: “[...] la France est en Amazonie. La plus grande frontière extérieure de la France c'est entre la Guyane et le Brésil, donc nous sommes là-bas"15 (REUTERS, 2019). Contudo, a proximidade territorial não faz com que seja possível a identificação, na Amazônia, da prática de um ataque do Estado brasileiro contra o Estado francês, possibilitando a este defender-se legitimamente.

\subsection{Manutenção da paz}

Afastada a possibilidade de legítima defesa na Amazônia, passa-se a examinar se trata-se de ameaça ou ruptura da paz internacional, que poderia ensejar uma intervenção internacional. Nesse caso, é necessário

14 “Aconteceu de o Brasil possuir um recurso global crítico - por razões puramente históricas - e sua destruição causaria dano a muitos Estados, se não ao planeta inteiro".

15 “[...] a França está na Amazônia. A mais extensa fronteira externa da França está entre a Guiana e o Brasil; logo, estamos lá". 
que se cumpra o devido processo legal previsto no Capítulo VII da Carta das Nações Unidas, segundo o qual é protagonista o Conselho de Segurança. De fato, é este órgão o competente para identificar os fatos que correspondam a uma ameaça ou ruptura da paz internacional, podendo, consequentemente, determinar medidas de coerção (DIHN; DAILLIER; PELLET, 2003).

É possível, com fundamento no art. 42 da Carta das Nações Unidas, que o Conselho de Segurança das Nações Unidas determine o emprego da força contra Estados que violem a obrigação de impedir, em seu território ou espaço de jurisdição nacional, a prática de atividade destrutiva que ponha em risco a paz.

Por se tratar de situação extraordinária, onde o exercício da violência torna-se lícito, o Conselho de Segurança deve autorizar a intervenção de modo expresso, pois o que garante a licitude do ato é a forma. Nos termos do art. 39 da Carta das Nações Unidas, cabe ao Conselho de Segurança determinar a existência de ameaça ou ruptura da paz internacional, podendo ordenar medidas para a manutenção ou restabelecimento da paz.

Nos termos do art. 48 da Carta das Nações Unidas, uma vez autorizada a intervenção para a manutenção da paz, os Estados executarão a decisão em nome da organização internacional. Nesse caso, não se trata de intervenção estrangeira, mas de intervenção internacional, pois feita sob os auspícios da organização internacional.

\subsection{Graves violações de direitos ambientais como ameaça à paz na Amazônia}

Em 24 de agosto de 2019, Franklin Foer ${ }^{16}$ publicou um artigo em The Atlantic, afirmando que:

The destruction of the Amazon is arguably far more dangerous than the weapons of mass destruction that have triggered a robust response. The consequences of the unfolding disaster - which will extinguish species and hasten a worst-case climate crisis - extend for eternity. To lose a fifth of the Amazon to deforestation would trigger a process known as 'dieback, 'releasing what The Intercept calls a 'doomsday bomb of stored carbon.' But the case for territorial incursion in the Amazon is far stronger than the justifications for most war. In the meantime, the planet chokes on old notions of sovereignty ${ }^{17}$.

16 Franklin Foer é jornalista e membro da New American [Foundation].

17 "A destruição da Amazônia é sem dúvida muito mais perigosa do que as armas de destruição em massa, que desencadearam uma resposta robusta. As consequências do desastre em curso - que extinguirá espécies e apressará uma ainda pior crise climática - estendem-se por toda a eternidade. Perder 
Trata-se de um argumento incisivo de que o que ocorre na Amazônia é mais grave do que ter armas de destruição em massa. Por isso, o desflorestamento amazônico é uma situação de risco à paz, sendo necessária uma resposta à altura da comunidade internacional. Segundo o autor, outras guerras foram feitas por muito menos.

É muito difícil definir a priori quais fatos colocam em risco a paz internacional. Como será visto, graves violações de direitos humanos têm sido consideradas suficientes para exigir medidas coercitivas de manutenção de paz. Mais difícil é a discussão sobre as interações entre isso com as violações de direitos ambientais. Autores sustentam que a degradação ambiental pode corresponder a uma ameaça à paz (GILLEY; KINSELLA, 2015). Ao se afastar da visão clássica de que a paz significa a inexistência de conflitos armados, uma intervenção internacional poderia ser implementada de modo mais amplo, alcançando a temática ambiental (KEMER; PEREIRA; BLANDO, 2016, p. 138).

A partir desse pressuposto, levando-se em consideração que uma intervenção para a manutenção da paz é situação extraordinária, deve-se concluir que apenas um dano ambiental transfronteiriço grave torná-la-ia possível, o que não resolve o problema. A dificuldade passa a ser a definição de dano ambiental transfronteiriço grave. Aquilo que se entende como "integridade territorial" é atualmente vista como "integridade ecossistêmica" (ECKERSLEY, 2007).

$\mathrm{Na}$ medida em que se procura garantir a paz internacional, o dano ambiental deve ser percebido para além das fronteiras nacionais do Estado. Trata-se de uma característica do fenômeno, cuja demonstração é menos problemática. O grande desafio aqui é identificar o grau de importância do dano ambiental. Sua gravidade deve ser diretamente proporcional ao risco de causar elevação das tensões internacionais.

Não se questiona a gravidade dos efeitos do processo atual de desmatamento da Amazônia. É notório também que os impactos desse processo são percebidos para além das fronteiras dos Estados amazônicos. Por fim, esses fatos têm causado efetivamente o aumento das tensões internacionais, como demonstram as manifestações recentes dos representantes dos Estados brasileiro e francês. Contudo, não está claro ser a situação uma ameaça à paz internacional. Para Foer, não há dúvidas de que se trata disso. Identificados os elementos materiais necessários, cabe

um quinto da Amazônia para o desmatamento desencadearia um processo conhecido como 'apoplexia, liberando o que The Intercept chama de 'bomba apocalíptica de carbono armazenado'. Mas o caso de incursão territorial na Amazônia é muito mais forte do que as justificativas para a maioria das guerras. Enquanto isso, o planeta se engasga com velhas noções de soberania". 
ao Conselho de Segurança identificar, no caso concreto, a ameaça à paz e determinar a intervenção na Amazônia, desde que os Estados envolvidos sejam membros das Nações Unidas, como acontece com o Brasil e a França.

\subsection{Graves violações de direitos humanos como ameaça à paz na Amazônia}

Além de graves violações de direitos ambientais, graves violações de direitos humanos também são suficientes para pôr em risco a paz internacional, que, por sua vez, pode ser base da decisão do Conselho de Segurança em favor de uma intervenção humanitária (SIPELER, 2007). Isso se deve ao fato de que a proteção de direitos humanos não compõe assunto do domínio reservado dos Estados (DIHN; DAILLIER; PELLET, 2003). Por esse motivo, não é necessário demonstrar o caráter transfronteiriço dos fatos para que os fatos interessem à comunidade internacional. O Estado deve exercer sua soberania territorial como meio de efetivação dos direitos humanos (CANÇADO TRINDADE, 2011).

Para que seja possível uma intervenção humanitária, é necessário que estejam presentes elementos relacionados a violações maciças, sistemáticas e em grande escala (SPIELER, 2007). Alguns autores chegam a afirmar que a intervenção só é possível em duas hipóteses: assassinato em massa e escravidão (MARTIN, 2005). Outros afirmam que uma intervenção só se dá diante da prática de genocídio (FIXDAL; SMITH, 1998). Por fim, há quem preveja a intervenção humanitária em caso de crimes contra a humanidade, que demandam uma resposta imediata da comunidade internacional (GUERREIRO, 2000).

Apesar das diversas correntes doutrinárias, pode-se afirmar que há consenso de que os crimes de competência ratione materiae do Tribunal Penal Internacional (TPI) são graves violações do Direito Internacional, cuja resposta pode ser extraordinariamente uma intervenção internacional autorizada pelo Conselho de Segurança das Nações Unidas como medida de manutenção da paz.

Nesse contexto é considerada grave violação de direitos humanos a transferência forçada de populações. De fato, o Estatuto do Tribunal Penal Internacional (TPI, 1998), em seu art. $7^{\circ}, d$, define como crime contra a humanidade a deportação ou transferência forçada de uma população, quando realizada em contexto de ataque, generalizado ou sistemático. Com certa frequência, as transferências forçadas de populações são 
acompanhadas de atos de genocídio, visando uma limpeza étnica (TPIY, 2009), que também podem ser examinados pelo TPI.

Com a consagração da noção de crimes contra a humanidade e genocídio como graves violações do Direito Internacional, desenvolveu-se a noção de que essas obrigações são jus cogens, não se tratando assim de assunto do domínio reservado dos Estados e interessando à comunidade internacional como um todo (PARAGUASSU, 2016). Como desdobramento disso, surge o princípio da "jurisdição universal", segundo o qual todos os Estados podem agir para punir indivíduos acusados da prática de crimes contra a humanidade e genocídio (GÓMEZ, 2008, p. 95). No exercício da jurisdição universal para julgar graves violações de direitos humanos, pode-se citar os exemplos da Espanha ${ }^{18}$, França ${ }^{19}$, Alemanha ${ }^{20}$ e Itália ${ }^{21}$, que tiveram a oportunidade de reconhecer expressamente que se trata de norma jurídica internacional geralmente válida.

Em face do princípio da jurisdição universal de combate à impunidade dos criminosos contra a humanidade ${ }^{22}$, passou-se a discutir a existência da obrigação jurídica internacional erga omnes de intervenção em socorro das vítimas de graves violações de direitos humanos. A dúvida recai sobre a possibilidade de os Estados usarem a força fora de seu espaço territorial ou de jurisdição nacional para impedir a ocorrência do ilícito internacional. Apesar da boa intenção moral, os Estados não têm o dever de intervenção humanitária (DIHN; DAILLIER; PELLET, 2003, p. 459). Porém, isso não significa que a intervenção humanitária não seja possível. Ao contrário, há intervenção possível, desde que determinada por um organismo internacional apropriado, como previsto no Capítulo VII da Carta das Nações Unidas ${ }^{23}$.

18 Por exemplo, Tribunal Supremo Espanhol, Sala Penal. Sentença de Recurso de Cassacão, de 25 de fevereiro de 2003, N. 803/2001; Audiência Nacional, Sala Penal. Apelação procedimento abreviado, de 10 de janeiro de 2006, N. 196/005.

19 Por exemplo, Corte de Cassação da França, Câmara Penal. Inadmissibilidade de Recurso de Cassação, de 3 de junho de 1998, Caso Klaus Barbie, Número do recurso: 87-84240.

20 Por exemplo, Tribunal Superior de Justiça de Düsseldorf. Caso Nikola Jorgic, Sentença de 26 de setembro de 1997, IV-26/96 2 StE 8/96.

21 Por exemplo, o Caso do Capitão SS Erich Priebke. Extraditado da Argentina para a Itália em 2 de novembro de 1995. Ver Tribunal Federal de Bariloche, 31 de maio de 1995, e Câmara Federal de Apelações, 23 de agosto de 1995, e Corte Suprema de Justiça da Nação, 2 de novembro de 1995. Condenação final pelo Tribunal Militar de Roma, em 22 de julho de 1997.

22 Em cumprimento do dever de memória, lembramos que pessoas acusadas de prática de crimes contra a humanidade no Brasil, durante o período da Ditadura, ainda estão impunes em razão de aplicação, no âmbito interno, da Lei de Anistia, considerada por órgãos internacionais, especialmente a Corte Interamericana de Direitos Humanos, contrária a norma imperativa de Direito Internacional geral. Vide Toledo e Bizawu (2018).

23 Por exemplo, o Conselho de Segurança das Nações Unidas identificou como ameaça à paz internacional a situação decorrente da declaração unilateral de independência, em 1965, pela minoria 


\subsubsection{Crimes contra a humanidade na Amazônia como ameaça à paz}

Em 19 de novembro de 2018, os advogados François Zimeray ${ }^{24}$ e Jessica Finelle publicaram um artigo em Le Monde, afirmando que alguns projetos apresentados por Bolsonaro, então candidato à presidência do Brasil, se implementados, "pourraient même relever de la qualification de crimes contre l'humanité, notamment en raison de transferts forcés de populations indigènes" 25 .

Importantes deslocamentos humanos podem acontecer quando da realização de grandes obras de engenharia como, por exemplo, a construção de usinas hidrelétricas. Também é possível que esses movimentos aconteçam como reação à expansão da fronteira agrícola ou ao aumento das atividades de mineração. Pode-se imaginar também a hipótese de o desmatamento e as queimadas serem utilizados como instrumentos de expulsão dos indígenas de suas terras tradicionais. Em todas as situações acima, haveria atos de retirada compulsória de indígenas, o que é condição para o crime contra a humanidade.

Contudo, só há deslocamento forçado quando a população afetada pela transferência não tenha demonstrado seu consentimento prévio, livre e informado. Há uma série de dificuldades práticas para demonstrar a existência da consulta prévia ${ }^{26}$ aos povos indígenas e tradicionais. Interessa aqui indicar apenas que, caso não tenha sido devidamente obtido o consentimento desses grupos humanos acerca de seu deslocamento, qualquer ato nesse sentido deve ser tratado como transferência forçada. De fato, diferente do abandono das terras, a transferência forçada representa necessariamente um movimento involuntário, impulsionado por mecanismos repressivos (DEMETRIO; KOZICKI, 2019, p. 156).

Além de forçada, a transferência de populações indígenas ou tradicionais só será considerada crime contra a humanidade, se praticada em um contexto de ataque generalizado ou sistemático (AMANI; SMIS, 2017). Por ataque generalizado ou sistemático contra uma população indígena, por exemplo, deve-se entender a prática de atos contrários à

branca na Rodésia do Sul e o regime de apartheid na África do Sul, que existiu entre 1948 e 1991.

24 François Zimeray é, desde 2008, diplomata francês e exerceu, entre 1999 e 2004, o mandato de deputado do Parlamento Europeu.

25 "poderiam mesmo ser qualificados como crimes contra a humanidade, especialmente em razão das transferências forçadas de populações indígenas".

26 A colega professora Dra ${ }^{a}$. Liana Amin Lima da Silva tem se destacado nas pesquisas sobre o direito de consulta e consentimento livre, prévio e informado dos povos indígenas e tribais na América Latina. 
permanência de tal população em suas terras tradicionalmente ocupadas, em cumprimento de um plano de Estado contrário à existência dessas pessoas (BUSSY, 2015). A discriminação contra a população deve ser a razão da transferência forçada, que se realiza em ataque generalizado ou sistemático (TPIR, 2003).

Quando o Estado propõe a construção de gigantes hidrelétricas, a expansão da fronteira do agronegócio ou a instalação de plantas de mineração na Amazônia, que obrigam o deslocamento de populações indígenas ou tradicionais, só se pode falar em crime contra a humanidade, se o fim do projeto instalado é atacar esses grupos humanos.

Apesar da dramaticidade da situação, não parece que os projetos na Amazônia sejam uma estratégia de ataque aos povos indígenas ou tradicionais. A finalidade é implementar políticas de desenvolvimento econômico, que, indiretamente, causam sérios danos à vida daquelas pessoas. Diante disso, é impossível tratar os movimentos populacionais, decorrentes da implementação das obras na Amazônia, como crime contra a humanidade.

\subsubsection{Genocídio na Amazônia como ameaça à paz}

Dentro do sistema internacional de proteção dos direitos humanos, o direito de propriedade coletiva das terras tradicionalmente ocupadas por indígenas tem sido garantido pela jurisprudência internacional como um direito associado à dependência material e imaterial de seus membros em relação ao território (TOLEDO; BENEDETTO, 2018). De fato, a Corte Interamericana de Direitos Humanos (CtIDH) - órgão jurisdicional internacional com competência para examinar violações ao Direito Internacional dos Direitos Humanos ${ }^{27}$ - decidiu que o exercício da soberania pelo Estado não implica o direito de negar a existência dos povos indígenas em suas terras tradicionais (CtIDH, 2012).

Quando há a imposição a um grupo étnico de condições de vida com o fim de causar sua destruição física, está-se diante da prática de genocídio. Logo é obrigação imperativa do Direito Internacional a abstenção da prática de atos em vista do desaparecimento de uma comunidade indígena amazônica (TOLEDO, 2019b). Ne medida em que a propriedade coletiva é condição indispensável para a sobrevivência de um povo indígena, o ato,

27 Dos nove Estados amazônicos, não são partes da Convenção Americana de Direitos Humanos a França - que se vincula à Convenção Europeia de Direitos Humanos (1950) -, a Guiana e a Venezuela. 
que não lhes garanta o exercício desse direito, pode ser identificado como um ato genocida. É possível que a violação da propriedade coletiva indígena corresponda efetivamente à ameaça de destruição do grupo enquanto tal.

Em relação ao Estado brasileiro, a CtIDH afirmou, em 2018, que seu direito interno dá prioridade à propriedade coletiva, em detrimento da propriedade privada. Por conta disso e em face das obrigações internacionais pertinentes, o Brasil já deveria ter concluído o processo de demarcação e desintrusão das terras indígenas (CtIDH, 2018). Sem isso, é impossível garantir o direito de propriedade coletiva a esses povos, nos termos do art. 21 da Convenção Americana de Direitos Humanos, o que pode colocar em risco sua sobrevivência como grupo.

Sobre a intenção de não mais demarcar terras indígenas, o presidente do Brasil, em discurso na Assembleia Geral das Nações Unidas, afirmou que: “[...] o Brasil não vai aumentar para $20 \%$ sua área já demarcada como terra indígena, como alguns chefes de Estado gostariam que acontecesse" (VERDÉLIO, 2019b). E acrescentou, sobre as terras indígenas já demarcadas, que:

O índio não quer ser latifundiário pobre em cima de terras ricas. Especialmente das terras mais ricas do mundo. É o caso das reservas Ianomâmi e Raposa Serra do Sol. Nessas reservas, existe grande abundância de ouro, diamante, urânio, nióbio e terras raras, entre outros.

Quando o presidente do Brasil declara estar disposto a impedir novas demarcações de terra indígena e rever aquelas já realizadas (VERDÉLIO, 2019a), há um contexto fático favorável ao genocídio na Amazônia, pois se trata de afirmação de que, intencionalmente, pretende-se privar determinados grupos humanos de condições materiais para sua sobrevivência como grupo. Se a demarcação das terras, garantindo o direito de propriedade coletiva, for condição para a sobrevivência de um determinado povo indígena, a omissão do Estado pode ser interpretada como ato genocida, dando margem a responsabilizações internacionais.

O genocídio perpetuado historicamente contra os povos indígenas avança atualmente com outro formato, por meio da tomada de suas terras tradicionais e a restrição de sua autonomia (HAGINO; QUINTANS, 2015). A proibição de genocídio é obrigação de jus cogens, reconhecida há décadas (RODAS, 1974). Logo, mesmo que o Estado denuncie o Pacto de São José da Costa Rica, a vedação de genocídio continua sendo juridicamente obrigatória. 


\subsubsection{Ecocídio na Amazônia como ameaça à paz}

Em 15 de setembro de 2016, o Escritório da Promotoria do Tribunal Penal Internacional publicou o documento intitulado Policy Paper on Case Selection and Priorisation, no qual se encontra a seguinte afirmação:

In this context, the Office will give particular consideration to prosecuting Rome Statute crimes that are committed by means of, or that result in, inter alia, the destruction of the environment, the illegal exploitation of natural resources or the illegal dispossession of land ${ }^{28}$ (OTP, 2016).

Trata-se de uma manifestação importante porque a Promotoria tem a função de dar início à ação penal junto ao TPI. Assim como se analisou a importância do Estatuto do TPI para a definição de grave violação contra a humanidade, é necessário constatar que a retomada da discussão sobre o ecocídio deve-se ao funcionamento do sistema judiciário internacional penal. De fato, a possibilidade de trazer o dano ambiental para o exercício da jurisdição do TPI é o que uma parte da doutrina tem chamado de ecocídio (BROCHADO NETO; MONT'ALVERNE, 2018).

Embora tenha sido retomada recentemente, a discussão doutrinária sobre o ecocídio teve seu início com a celebração dos primeiros tratados internacionais dedicados à proteção do meio ambiente, tendo como pano de fundo o uso do agente laranja pelos Estados Unidos durante a Guerra do Vietnã (ZIERLER, 2011). Desde o início, a noção de ecocídio foi associada ao dano ambiental significativo no território de um Estado, produzido para pôr em risco a sobrevivência de seus habitantes (SALAZAR, 2017).

O ecocídio tem a importância de demonstrar dramaticamente a vinculação necessária entre meio ambiente equilibrado e dignidade humana (COLOMBO, 2007). Não se trata de elemento de proteção ambiental em si mesmo. É possível assim que se destrua indiretamente um grupo humano, destruindo diretamente seu território, fauna, flora e ecossistema como um todo (TABÍO; CORONA, 1972).

A valorização da questão ambiental se dá indiretamente, uma vez que a proteção do meio ambiente é condição para a sobrevivência de determinados grupos humanos. Assim como acontece com o genocídio, os atos de ecocídio não se dirigem contra um indivíduo, mas a um grupo de seres humanos, considerado em sua totalidade (FRAGOSO, 1973). Existe, portanto, uma íntima conexão entre genocídio e ecocídio, embora este seja

28 "Nesse contexto, o Escritório prestará especial atenção ao julgamento de crimes do Estatuto de Roma cometidos por meio de, ou que resultem em, inter alia, a destruição do meio ambiente, o aproveitamento ilegal de recursos naturais ou a desapropriação ilegal de terras". 
mais amplo do que aquele (GREENE, 2019).

Em virtude disso, o ecocídio só se realiza em face da ação ou omissão do Estado, cujo propósito é destruir um determinado grupo humano, comprometendo irremediavelmente as coordenadas ambientais em que vive. É o caso, por exemplo, da destruição das florestas em Bosawás, na Nicarágua, que tem sido vista por líderes indígenas mayagna ${ }^{29}$ como prática de ecocídio (FERMÍN, 2014).

Sobre o ecocídio na Amazônia, o presidente da França declarou à imprensa, em 23 de agosto de 2019, que: "Il faut stopper un processus de déforestation industrialisé un peu partout, on a véritablement un écocide qui est en train de se développer à travers l'Amazonie et pas simplement au Brésil" ${ }^{30}$ (REUTERS, 2019).

Sobre isso escreveram Lloyd Axworthy ${ }^{31}$ e Allan Rock ${ }^{32}$ um artigo, cuja tradução foi publicada em $O$ Estado de S. Paulo. No texto, os autores afirmam que a soberania não deve ser uma barreira à intervenção, quando um Estado se vincula a práticas de genocídio ou outras atrocidades em massa em seu território. Em seguida, afirmam que as políticas de aceleração do aquecimento global são atrocidades em massa relacionadas à destruição ambiental. Um exemplo dessas atrocidades seriam os incêndios na Amazônia, o que se configuraria como ecocídio a ser confrontado diretamente pelos demais Estados por meio de uma intervenção internacional (AXWORTHY; ROCK, 2019).

Uma intervenção humanitária em razão de cometimento de ecocídio na Amazônia brasileira só seria possível, se se demonstrasse que o desmatamento e as queimadas acontecem com a finalidade de exterminar grupos humanos. Isso poderia ser sustentado em relação a situações como aquela identificada como o "dia do fogo", em que, por meio de uma ação orquestrada, produtores rurais incendiaram intencionalmente a floresta amazônica, a fim de demonstrar o interesse em trabalhar naquelas áreas (MPF, 2019). Caso fosse demonstrada a intenção de colocar em risco a existência de determinadas populações tradicionais, seria possível falar em ecocídio na Amazônia.

29 A Corte Interamericana de Direitos Humanos já julgou um caso envolvendo o povo indígena mayagna. Vide Caso da Comunidade Mayagna (Sumo) Awas Tingni vs. Nicarágua, sentença de 31 de agosto de 2001.

30 "É necessário interromper um processo de desmatamento industrializado em todo o lado, há um verdadeiro ecocídio que está se desenvolvendo através da Amazônia e não apenas no Brasil".

31 Presidente do Conselho Mundial de Refugiados e ex-ministro das Relações Exteriores do Canadá. 32 Presidente Emérito da Universidade de Ottawa e ex-embaixador canadense nos Estados Unidos. 


\section{CONCLUSÃO}

Os efeitos da destruição da Amazônia brasileira não se restringem ao território nacional, podendo alcançar seus vizinhos amazônicos e não amazônicos. Apesar de ser regra do Direito Internacional, a não intervenção não é absoluta. Há hipóteses em que o sistema jurídico prevê a intervenção em assuntos internos do Estado por meio do uso da força estrangeira ou internacional, quais sejam a legítima defesa e a manutenção da paz.

$\mathrm{Na}$ primeira hipótese, é necessário haver um ato anterior de agressão ou ataque, o que corresponde tradicionalmente à agressão armada. Em tempos recentes, também se permite a legítima defesa quando a sobrevivência do Estado estiver em risco, mesmo sem o uso de armas, o que é importante quando se pensa em danos ambientais. De qualquer forma, é indispensável que o fato seja considerado um ataque contra a sobrevivência do Estado, isto é, que seja um ato intencional que ponha em risco elemento constitutivo do Estado. Nesse sentido, por mais grave que seja, a destruição da Amazônia não é um ato de ataque contra outro Estado, por mais próximo que esteja, como é o caso da França. Logo, não se pode falar em exercício de legítima defesa em face da atual crise internacional amazônica.

$\mathrm{Na}$ segunda hipótese, a existência de ameaça ou ruptura da paz internacional é determinada exclusivamente pelo Conselho de Segurança das Nações Unidas, que pode ordenar o uso da força em um Estado membro para o restabelecimento da paz. A nenhum Estado é dado o direito de adotar unilateralmente medidas para a manutenção da paz em território estrangeiro. Logo, uma intervenção internacional na Amazônia só seria possível por decisão do Conselho de Segurança, em razão de o Brasil ser membro das Nações Unidas.

Apesar da importância dos direitos humanos para a sociedade internacional contemporânea, como regra, não há um direito de intervenção humanitária. Por não haver conflito armado na Amazônia brasileira, uma intervenção humanitária só seria possível, caso o Conselho de Segurança identificasse a ruptura ou ameaça à paz por graves violações de direitos humanos, como os crimes contra a humanidade e o genocídio. No contexto amazônico, a figura do ecocídio, que tem conexões com o genocídio, também pode ser indicada como hipótese de grave violação de direitos humanos.

Como crime contra a humanidade na Amazônia, a ameaçar a paz internacional, dando margem à intervenção internacional, cogita-se em falar de transferência forçada das populações indígenas de suas terras tradicionais como desdobramento da implementação de grandes projetos estruturais 
do Estado. Apesar da gravidade dessa situação, que se relaciona à falta do consentimento prévio, livre e informado dessas populações, só haveria crime contra a humanidade se houvesse a intenção de exterminar aquelas pessoas, o que não acontece na atual crise amazônica.

Como genocídio na Amazônia, que ameaçaria a paz internacional, dando margem à intervenção internacional, é possível identificá-lo a partir da violação do direito de propriedade coletiva, quando da falta de demarcação e desintrusão de terras indígenas por parte do Estado. Se se coloca intencionalmente em risco a sobrevivência do povo indígena amazônico, que depende de suas terras para existir enquanto grupo, pode-se falar em prática genocida.

Como ecocídio na Amazônia, a ameaçar a paz internacional, dando margem à intervenção internacional, o desmatamento e a queima da floresta podem ser tratados como estratégia de extermínio de determinados grupos humanos. Nesse caso, é imperativa a demonstração de que os danos ambientais são causados com a finalidade última de comprometer a existência de uma população enquanto tal.

Conclui-se assim a possibilidade de haver genocídio e ecocídio, o que poderia fundamentar como elemento material uma decisão de intervenção internacional na Amazônia. Entretanto, não basta a presença da condição material, é necessário o cumprimento da condição formal, qual seja a decisão do organismo internacional competente, como é o caso do Conselho de Segurança das Nações Unidas.

Não há, portanto, a possibilidade jurídica de intervenção unilateral estrangeira para a manutenção da paz internacional. Uma iniciativa dessas, que se dê à margem do mecanismo de controle das Nações Unidas, deve ser tratada como ato ilícito internacional praticado pelos Estados interventores, como aconteceu, por exemplo, na Iugoslávia ${ }^{33}$, em 1999, e no Iraque ${ }^{34}$, em 2003.

33 De 24 de março a 10 de junho de 1999, durante a Guerra do Kosovo, sem a autorização prévia do Conselho de Segurança das Nações Unidas, a força aérea vinculada à Organização do Tratado do Atlântico Norte (OTAN) bombardeou a Iugoslávia com o intuito de interromper atos de violência praticados pelo governo contra a minoria albanesa. Sobre essa intervenção da OTAN, a Comissão Internacional Independente sobre o Kosovo (IICK) publicou, em 23 de outubro de 2000, um relatório em que considera o ato ilícito. Essa ilicitude deve-se tão somente à ausência dos requisitos formais para a intervenção, pois presentes estavam as condições materiais (graves violações de direitos humanos). Vide IICK. The Kosovo Report. Oxford: Oxford University Press, 2000.

34 Em 19 de março de 2003, sem a autorização prévia do Conselho de Segurança das Nações Unidas, as forças armadas dos Estados Unidos, Reino Unido, Austrália e Polônia invadiram o Iraque com o intuito de tomar suas armas de destruição em massa, o que foi considerado pelo então secretário-geral das Nações Unidas, Kofi Annan, como um ato ilícito. Sobre o tema, vide SIFRIS, Ronli. Operation Iraqi Freedom: Unites States v Iraq - the Legality of the War. Melbourne Journal of International Law, v. 4, 2003, p. 521-560. 


\section{REFERÊNCIAS}

AMANI, C. E.; SMIS, S. Le régime des obligations positives de prévenir et de poursuivre à défaut d'extrader ou de remise prévues dans le texte des projets d'articles sur les crimes contre l'humanité provisoirement adoptés par la Commission du droit international. Revue Québécoise de Droit International, Quebec, v. 30, n. 1, p. 1-39, 2017.

AMAZONIE: les membres du G7 vont annoncer une aide d'urgence de 20 millions de dollars. Le Figaro, 26 ago. 2019. Disponível em: http:// www.lefigaro.fr/sciences/amazonie-les-membres-du-g7-vont-annoncer-une-aide-d-urgence-de-20-millions-de-dollars-20190826. Acesso em: 8 nov. 2019.

AMORIM, F. Bolsonaro defende reduzir áreas de conservação e pede "Cancún" brasileira. UOL Notícias, 11 jul. 2019. Disponível em: https:// noticias.uol.com.br/politica/ultimas-noticias/2019/07/11/bolsonarodefende-reduzir-areas-de-conservacao-e-pede-cancun-brasileira.htm. Acesso em: 8 nov. 2019.

AXWORTHY, L.; ROCK, A. Fogo na Amazônia: o presidente do Brasil está cometendo ecocídio. Devemos pará-lo. O Estado de S. Paulo, 30 ago. 2019. Disponível em: https://sustentabilidade.estadao.com.br/noticias/ geral,fogo-na-amazonia-o-presidente-do-brasil-esta-cometendo-ecocidionos-devemos-para-lo,70002988990. Acesso em: 8 nov. 2019.

BROCHADO NETO, D.A.; MONT’ALVERNE, T. C. F. Ecocídio: proposta de uma política criminalizadora de delitos ambientais internacionais ou tipo penal propriamente dito? Revista Brassileira de Políticas Públicas, Brasília, v. 8, n. 1, p. 209-226, 2018.

BUSSY, F. Le crime contre l'humanité, une étude critique. Témoigner. Entre Histoire et Mémoire, v. 115, 2013. p. 135-148.

CANÇADO TRINDADE, A. A. La recta ratio dans les fondements du Jus Gentium comme Droit International de l'Humanité. Revista da Faculdade de Direito da UFMG, Belo Horizonte, n. 58, p. 91-122, 2011.

CANÇADO TRINDADE, A. A. International law for humankind: towards a new jus gentium (II). General Course on Public International Law, v. 317. In: Recueil des Cours de l'Académie de Droit international de la Haye. Leiden: Brill/Nijhoff, 2005. p. 9-312. 
CHAGAS, A. M.; HECKTHEUER, P. A.; HeCKTHEUER, F. R. O discurso da internacionalização da Amazônia: do imaginário das narrativas à racionalidade instrumental dos projetos. Novos Estudos Jurídicos, Itajaí, v. 22, n. 3, p. 849-876, 2017.

CIJ - COUR INTERNATIONALE DE JUSTICE. Activités militaires et paramilitaires au Nicaragua et contre celui-ci (Nicaragua c. ÉtatsUnis d'Amérique). Arrêt du 26 novembre 1984. Recueil des arrêts, avis consultatifs et ordonnances de la Cour internationale de Justice, 1984. p. 392.

CIJ - COUR INTERNATIONALE DE JUSTICE. Licéité de la menace ou de l'emploi d'armes nucléaires. Avis consultatif du 8 juillet 1996. Recueil des arrêts, avis consultatifs et ordonnances de la Cour internationale de Justice, 1996. p. 226.

CIJ - COUR INTERNATIONALE DE JUSTICE. Projet Gabčikovo-Nagymaros (Hongrie c. Slovaquie). Arrêt du 25 septembre 1997. Recueil des arrêts, avis consultatifs et ordonnances de la Cour internationale de Justice, 1997. p. 7.

COLOMBO, S. Da noção de soberania dos Estados à noção de ingerência ecológica. Revista Direitos Fundamentais \& Democracia, v. 1, 2007. Disponível em: http://revistaeletronicardfd.unibrasil.com.br/index.php/ rdfd/article/view/75/74. Acesso em: 11 nov. 2019.

COLOMBO, S. O princípio da soberania dos Estados face ao Direito Internacional do Ambiente. UNOPAR Cientifica, Ciências Jurídicas Empresariais, Londrina, v. 9, n. 1, p. 5-12, mar. 2008.

COSTA, A. A. O poder constituinte e o paradoxo da soberania limitada. Teoria e Sociedade, Belo Horizonte, n. 19.1, p. 198-227, jan./jun. 2011.

CtIDH - CORTE INTERAMERICANA DE DIREITOS HUMANOS. Caso da Comunidade Mayagna (Sumo) Awas Tingni vs. Nicarágua. Sentença de 31 de agosto de 2001. Corte Interamericana de Direitos Humanos, 2001.

CtIDH - CORTE INTERAMERICANA DE DIREITOS HUMANOS. Caso do Povo Indígena Kichwa de Sarayaku vs. Equador. Sentença de 27 de junho de 2012. Corte Interamericana de Direitos Humanos, 2012.

CtIDH - CORTE INTERAMERICANA DE DIREITOS HUMANOS. Caso do Povo Indígena Xucuru e seus membros vs. Brasil. Sentença de 5 de fevereiro de 2018. Corte Interamericana de Direitos Humanos, 2018. 
DAILLIER, P.; FORTEAU, M.; PELLET, A. Droit international public. $8^{\mathrm{e}}$ éd. Paris: L.G.D.J., 2009.

DEMETRIO, A.; KOZICKI, K. A (in)justiça de transição para os povos indígenas no Brasil. Direito e Praxis, Rio de Janeiro, v. 10, n. 1, p. 126$-169,2019$.

DINSTEIN, Y. Guerra, agressão e legitima defesa. Barueri: Manole, 2004. DIHN, N. Q.; DAILLIER, P.; PELLET, A. Direito Internacional público. 2. ed. Lisboa: Fundação Calouste Gulbenkian, 2003.

ECKERSLEY, R. Ecological intervention: prospects and limits. Ethics \& International Affairs, v. 21, n. 3, p. 293-316, 2007.

FERMÍN, C. La gran deforestación latinoamericana. Ozono mío. Revista de Derecho Ambiental, n. 73, 2014.

FIXDAL, M.; SMITH, D. Humanitarian Intervention and Just War. Mershon International Studies Review, New Jersey, v. 42, n. 2, p. 283-312, 1998.

FOER, F. The Amazon fires are more dangerous than WMDs. The Atlantic, 24 ago. 2019. Disponível em: https:/www.theatlantic.com/ideas/archive/2019/08/amazon-fires-show-limits-sovereignty/596779/. Acesso em: 8 nov. 2019.

FRAGOSO, H. C. Genocídio. Revista de Direito Penal, São Paulo, n. 9/10, p. 27-36, 1973.

GILLEY, B.; KINSELLA, D. Coercing Climate Action. Survival, London, v. 57, n. 2, p. 7-28, 2015.

GÓMEZ, J. M. Globalização dos Direitos Humanos, legado das ditaduras militares no Cone Sul latino-americano e justiça transicional. Direito, Estado e Sociedade, Rio de Janeiro, n. 33, p. 85-130, 2008.

GOUVEIA, J. B. O uso da força no Direito Internacional Público. Revista Brasileira de Estudos Políticos, Belo Horizonte, n. 107, p. 149-200, 2013.

GREENE, A. The Campaign to Make Ecocide an International Crime: Quixotic Quest or Moral Imperative? Fordham Environmental Law Review, v. 30, n. 3, p. 1-48, 2019. 
GUERREIRO, S. Intervenção quase humanitária. Revista da Faculdade de Direito da Universidade de Lisboa, Lisboa, v. 41, n. 2, p. 887-915, 2000.

HAGINO, C. H.; QUINTANS, M. T. D. O reconhecimento de povos tradicionais e os usos contra-hegemônicos do direito no Brasil: entre a violência e a emancipação social. Revista Direito e Práxis, Rio de Janeiro, v. 6, n. 10, p. 598-644, 2015.

HOFFMANN, S. The ethics and politics of humanitarian intervention. 3. ed. Notre Dame: University of Notre Dame, 2003.

IICK - INDEPENDENT INTERNATIONAL COMMISSION ON KOSOVO. The Kosovo Report. Oxford: Oxford University Press, 2000.

INPE - INSTITUTO NACIONAL DE PESQUISAS ESPACIAIS. Monitoramento dos focos ativos por estado: comparação do total de focos ativos detectados pelo satélite de referência em cada mês, no período de 1998 até 12 set. 2019. Programa Queimadas, 13 set. 2019. Disponível em: http:// queimadas.dgi.inpe.br/queimadas/portal-static/estatisticas_estados/. Acesso em: 8 nov. 2019.

JOHNSON, B. [s.1.], 23 ago. 2019, 12:25 PM. Twitter: @ BorisJohnson. Disponível em: https://twitter.com/BorisJohnson/ status/1164921613864853506?s=20. Acesso em: 8 nov. 2019.

KEMER, T.; PEREIRA, A. E.; BLANCO, R. A construção da paz em um mundo em transformação: o debate e a crítica sobre o conceito de peacebuilding. Revista de Sociologia e Política, Curitiba,v. 24, n. 60, p. 137-150, 2016.

L'AMAZONIE, bien commun universel. Le Monde, 24 ago. 2019. Disponível em: https://www.lemonde.fr/idees/article/2019/08/24/1-amazonie-bien-commun-universel_5502406_3232.html. Acesso em: 8 nov. 2019.

MACRON, E. [s.1.], 22 ago. 2019, 4:14 PM. Twitter: @ EmmanuelMacron. Disponível em: https://twitter.com/EmmanuelMacron/ status/1164616868080103425?s=20. Acesso em: 8 nov. 2019.

MARQUES, L. Capitalismo e colapso ambiental. Campinas: Unicamp, 2015.

MARTIN, I. Just wars and humanitarian interventions. Journal of Social Philosophy, New Jersey, v. 36, n. 4, p. 439-456, 2005. 
MPF. Dia do fogo. Ministério Público Federal. Procuradoria da República no Município de Itaituba. 22 ago. 2019. Disponível em: http://www.mpf. $\mathrm{mp} . \mathrm{br} / \mathrm{pa} / \mathrm{sala}$-de-imprensa/documentos/2019/dia-do-fogo-nf-instaurar. pdf. Acesso em: 8 nov. 2019.

OTP. Policy Paper on Case Selection and Priorisation. Office of the Prosecutor, International Criminal Court, 15 set. 2016. Disponível em: https:// www.icc-cpi.int/itemsDocuments/20160915_OTP-Policy_Case-Selection_Eng.pdf. Acesso em: 8 nov. 2019.

PARAGUASSU, L. Bolsonaro vê "psicose ambiental” e diz que Inpe divulga dados "mentirosos" sobre desmatamento. Reuters, 19 jul. 2019. Disponível em: https://noticias.uol.com.br/ultimas-noticias/reuters/2019/07/19/ bolsonaro-diz-que-ha-psicose-ambiental-no-pais-e-acusa-inpe-por-dados-mentirosos-de-desmatamento.htm. Acesso em: 8 nov. 2019.

PIOVESAN, F. Proteção internacional dos direitos humanos: desafios e perspectivas. Revista de Direito Internacional e Econômico, Brasília, n. 2, ano 1, p. 85-99, 2003.

PUTTI, A. Bolsonaro: "Enquanto eu for presidente, não tem demarcação de terra indígena”. Carta Capital, 16 ago. 2019. Disponível em: https:// www.cartacapital.com.br/politica/bolsonaro-enquanto-eu-for-presidentenao-tem-demarcacao-de-terra-indigena/. Acesso em: 8 nov. 2019.

REUTERS. LEAD 1 - Macron proposera au G7 un train de mesures concrètes pour l'Amazonie. Reuters, 23 ago. 2019. Disponível em: https:// fr.reuters.com/article/idFRL5N25J51A. Acesso em: 8 nov. 2019.

RODAS, J. G. Jus Cogens em Direito Internacional. Revista da Faculdade de Direito da USP, São Paulo, v. 69, n. 2, p. 125-136, 1974.

SALAZAR, M. A. C. Hacia la creación de la Corte Internacional de Justicia Ambiental. Revista Temas Socio Jurídicos, v. 36, n. 72, p. 197-212, 2017.

SASSINE, V. Nova corrida pelo ouro na maior reserva indígena cria tensão e rastro de destruição. $O$ Globo, 5 ago. 2019. Disponível em: https:// oglobo.globo.com/brasil/nova-corrida-pelo-ouro-na-maior-reserva-indigena-do-pais-cria-tensao-rastro-de-destruicao-23853619. Acesso em: 8 nov. 2019.

SCHMITT, M. N. Cyber Operations and the Jus in Bello: Key Issues. Naval War College International Law Studies, 2011. Disponível em: https://ssrn. com/abstract=1801176. Acesso em: 8 nov. 2019. 
"SE NÃO MUDAR, saímos fora", diz Bolsonaro sobre Acordo de Paris. Último Segundo, 13 dez. 2018. Disponível em: https://ultimosegundo. ig.com.br/politica/2018-12-13/jair-bolsonaro-acordo-paris.html. Acesso em: 8 nov. 2019.

SIFRIS, R. Operation Iraqi Freedom: Unites Sates v Iraq - the Legality of the War. Melbourne Journal of International Law, Melbourne, v. 4, p. 521-560, 2003.

SILVEIRA, E. As águas e o ar: rios da Amazônia liberam 1\% do gás carbônico emitido pelas atividades humanas no planeta. Pesquisa Fapesp, São Paulo, n. 155, p. 52-54, 2009.

SOUZA, R. Bolsonaro diz querer filho na embaixada para viabilizar exploração de terra. Correio Braziliense, 27 jul. 2019. Disponível em: https://www.correiobraziliense.com.br/app/noticia/politica/2019/07/27/ interna_politica,774165/bolsonaro-diz-querer-filho-na-embaixada-paraviabilizar-exploracao-de.shtml. Acesso em: 8 nov. 2019.

SPIELER, P. A indeterminação do conceito de intervenção humanitária. Direito, Estado e Sociedade, Rio de Janeiro, n. 31, p. 150-174, 2007.

TABÍO, F. Á.; CORONA, E. La doctrina criminal de la vietnamización. Nixon convicto de los delitos de genocidio, ecocidio y biocidio. Revista Cubana de Derecho, n. 1, p. 161-177, 1972.

THE ECONOMIST. Deathwatch for the Amazon: Brazil has the power to save Earth's greatest fores - or destroy it. The Economist, 1 ago. 2019. Disponível em: https://www.economist.com/leaders/2019/08/01/ deathwatch-for-the-amazon. Acesso em: 8 nov. 2019.

TOLEDO, A. P. A Amazônia no Direito Internacional. Belo Horizonte: Arraes, 2015.

TOLEDO, A. P. A Guiana Francesa e a Amazônia. In: COSTA, B. S. Pan-Amazônia: o ordenamento jurídico na perspectiva das questões socioambientais e da proteção ambiental. Belo Horizonte: Dom Helder Câmara, 2016. p. 183-236.

TOLEDO, A. P. Amazônia: soberania ou internacionalização. Belo Horizonte: Arraes, 2012.

TOLEDO, A. P. Direito Internacional e Biopirataria. Belo Horizonte: D’Plácido, 2019a. 
TOLEDO, A. P. Reconhecimento da propriedade coletiva indígena no Sistema Interamericano de Direitos Humanos e seus desdobramentos na Amazônia. In: BARROSO, L. A.; MANIGLIA, E.; MIRANDA, A. G. Lei Agrária Nova: a Biblioteca Científica de Direito Agrário, Agroambiental, Agroalimentar e do Agronegócio. v. VI. Curitiba: Juruá, 2019b. p. 121-138.

TOLEDO, A. P.; BENEDETTO, S. D. Guiana Francesa. In: COSTA, B. S. Povos originários da Amazônia internacional. Rio de Janeiro: Lumen Juris, 2018. p. 139-174.

TOLEDO, A. P.; BIZAWU, K. O Brasil em São José da Costa Rica: 20 anos do reconhecimento da jurisdição contenciosa da Corte Interamericana de Direitos Humanos. Veredas do Direito, v. 15, n. 33. Belo Horizonte, p. 13-50, 2018.

TPIR - TRIBUNAL PENAL INTERNATIONAL POUR LE RWANDA. Le Procureur c. Laurent Semanza (Affaire n. ICTR-97-20-T). Jugement et sentence. Chambre de première instance du Tribunal Pénal International pour le Rwanda, 15 maio 2003. Disponível em: https://unictr.irmct. org/sites/unictr.org/files/case-documents/ictr-97-20/trial-judgements/ fr/030515.pdf. Acesso em: 8 nov. 2019.

TPIY - TRIBUNAL PENAL INTERNATIONAL POUR L'EXYOUGOSLAVIE. Résumé du jugement dans l'affaire Milutinović et consorts. Tribunal Pénal International pour l'ex-Yougoslavie, 26 fev. 2009. Disponível em: http://www.icty.org/x/cases/milutinovic/tjug/ fr/090226resume.pdf. Acesso em: 8 nov. 2019.

TRINDADE, G. Aumento do nível do mar pode causar danos ambientais e extinção de Estados insulares. IBDMAR, 21 ago. 2019. Disponível em: http://www.ibdmar.org/2019/08/aumento-do-nivel-do-mar-pode-causar-danos-ambientais-e-extincao-de-estados-insulares/. Acesso em: 8 nov. 2019.

UNITED NATIONS. Award in the arbitration regarding the delimitation of the maritime boundary between Guyana and Suriname. Award of 17 September 2007. Reports of International Arbitral Awards, v. XXX, p. 1-144, 2012.

UNITED NATIONS. Trail smelter case: (United States, Canada). Reports of International Arbitral Awards, v. III, p. 1.965, 2006. 
VERDÉLIO, A. Bolsonaro diz que não fará demarcação de terras indígenas. Agência Brasil, 16 ago. 2019a. Disponível em: http://agenciabrasil.ebc. com.br/politica/noticia/2019-08/bolsonaro-diz-que-nao-fara-demarcacaode-terras-indigenas. Acesso em: 8 nov. 2019.

VERDÉLIO, A. Veja a íntegra do discurso de Bolsonaro na Assembleia Geral da ONU. Agência Brasil, 24 set. 2019b. Disponível em: http://agenciabrasil.ebc.com.br/politica/noticia/2019-09/presidente-jair-bolsonaro-discursa-na-assembleia-geral-da-onu. Acesso em: 8 nov. 2019.

VILLAS BOAS, G. [s.1.], 22 ago. 2019, 11:00 PM. Twitter: @Gen_ VillasBoas. Disponível em: https://twitter.com/Gen_VillasBoas/status/1164719139413536774?s=20. Acesso em: 8 nov. 2019.

VITÉ, S. Typology of armed conflicts in international humanitarian law: legal concepts and actual situations. International Review of the Red Cross, Cambridge, v. 91, n. 873, p. 69-94, 2009.

WALT, S. M. Who will save the Amazon (and how)? Foreign Policy, 5 ago. 2019. Disponível em: https://foreignpolicy.com/2019/08/05/whowill-invade-brazil-to-save-the-amazon/. Acesso em: 8 nov. 2019.

WATANABE, P. Desmatamento na Amazônia em agosto cresce 222\% em relação ao mesmo mês de 2018. Folha de S. Paulo, 8 set. 2019. Disponível em: https:/www1.folha.uol.com.br/ambiente/2019/09/desmatamento-na-amazonia-em-agosto-cresce-222-em-relacao-ao-mesmo-mes-de-2018. shtml?loggedpaywall. Acesso em: 8 nov. 2019.

ZIERLER, D. The invention of ecocide: Agent Orange, Vietnam, and the scientists who changed the way we think about the environment. Athens: University of Georgia Press, 2011.

ZIMERAY, F.; FINELLE, J. Les projets anti-écologiques de Bolsonaro créent un risque pour les entreprises. Le Monde, 19 nov. 2018. Disponível em: https://www.lemonde.fr/idees/article/2018/11/19/les-projets-anti-ecologiques-de-bolsonaro-creent-un-risque-pour-les-entreprises_5385573_3232.html. Acesso em: 8 nov. 2019.

Artigo recebido em: 01/10/2019

Artigo aceito em: 05/11/2019 


\section{Como citar este artigo (ABNT):}

CAVALLO, G. J. A.; TOLEDO, A. P.; BIZAWU, K. Condições jurídicas internacionais de intervenção na Amazônia. Veredas do Direito, Belo Horizonte, v. 16, n. 36, p. 91-122, set/dez. 2019. Disponível em: http:// www.domhelder.edu.br/revista/index.php/veredas/article/view/1669. Acesso em: dia. mês. ano. 